\title{
The temporal and spatial scales of rocky coast geomorphology: A Commentary
}

David M. Kennedy ${ }^{1 *}$, Martin A. Coombes ${ }^{2}$, Derek N. Mottershead ${ }^{3}$

${ }^{1}$ School of Geography, The University of Melbourne, Parkville Vic 3010, Australia

${ }^{2}$ Oxford Rock Breakdown Laboratory, School of Geography and the Environment, University of Oxford, South Parks Road, Oxford, OX1 3QY

${ }^{3}$ Department of Geography, University of Portsmouth, Buckingham Building, Lion Terrace, Portsmouth, Hampshire, UK PO5 $1 \mathrm{HE}$

*Corresponding Author, davidmk@unimelb.edu.au, +61 383449168

\section{Abstract}

Rocky shores are complex landforms that result from marine erosion and subaerial weathering. They are time-integrated features where their present day form is the result of instantaneous erosion, often on the millimetre to sub-metre scale, occurring for centuries to millennia. As a result, research on rocky coasts focuses on a range of temporal and spatial scales from granular-scale swelling of a rock surface and instantaneous wave impact to modelling millennial-scale sea level drivers. The challenge for rocky coast researchers is either to upscale or to downscale their results to the humantimescales of greatest interest to managers. The research presented in Earth Surface Processes and Landforms over the past 3 years highlights the range of spatial and temporal approaches to the study of coastal cliffs and shore platforms. We identify a key temporal and spatial gap in current research. Seasonal - annual timeframes over hundreds of metres to kilometre scale studies appear to be lacking and are likely critical in understanding the future evolution of rocky coasts, especially their response to climate change.

\section{Introduction}

Rocky coasts are erosional landscapes. Their form at a particular instant in time is a function of how they resist erosive processes as they retreat landwards. Erosion is driven by marine processes acting on a surface formed in materials that have been weakened through subaerial weathering. The

This is the author manuscript accepted for publication and has undergone full peer review but has not been through the copyediting, typesetting, pagination and proofreading process, which may lead to differences between this version and the Version of Record. Please cite this article as doi: $10.1002 /$ esp.4150

This article is protected by copyright. All rights reserved. 
inherent strength of the lithology in which the coast is formed provides a critical boundary condition on the potential landscape that can be formed. That is, rock mechanical strength properties will determine the size of the steep cliff edifice that can form, as well as the presence and geomorphologic character of fronting shore platforms.

The timescale on which these processes occur is highly variable as also is the spatial location on which they act within the coastal zone. For example, wave energy on a microtidal shore platform tends to be concentrated at its seaward edge (Ogawa et al., 2014) with subaerial weathering of greater importance where wetting and drying cycles are most frequent and where the mediating effects of biological activity may be greatest (Gowell et al., 2015; Moses et al., 2015). These erosional processes occur over the instantaneous scale (minutes - hours) with waves removing material already weakened by subaerial weathering or directly plucking blocks from the cliffs and platform surface. Erosion over the instantaneous scale for millennia leads to the current form observed on the coast.

The fundamental difficulty in understanding rock coast evolution directly relates to the issue of the scale of the driving processes and the age of landform systems. This is because numerous feedbacks exist between erosive and weathering processes making it difficult to reconcile field measurements with current geomorphic form. For this reason, geomorphologists have resorted to a range of techniques from time-space substitution to theoretical models to explain landform evolution.

The research reported in Earth Surface Processes and Landforms (ESPL) over the past 3 years on shore platforms and sea cliffs highlights the range of scales over which these landforms systems operate. In this special issue of ESPL we explore the evolution of rock coast systems at a range of spatial and temporal scales (Figure 1).

\section{Instantaneous Scale}

At the shortest temporal scale, wave breaking occurs and is the primary energy input that both removes material loosened by subaerial weathering and directly erodes unweathered rock. In the work of Ogawa et al. (2015), they show that wave energy transfer across a semi-horizontal platform is a function of the relative submergence of the platform edge. While wave energy on the edge was a function of offshore conditions, at the base of the landward cliff energy was independent of the deep water wave climate and more a function of the water depth on the platform surface. The energy expenditure of waves breaking at the rear of the platform is not however solely confined to the platform itself. Microseismic energy is transferred into the landward cliff with cliff top vibrations being correlated to significant wave height and water maximum depth at the cliff base (Young et al., 2016). While wind-generated waves of gravity to infragravity frequency are the primary energy 
input, the instantaneous impact of longer period tsunami waves also can drive landscape formation in some circumstances, as is observed in the erosional scars on the platforms and cliffs of the Maltese Islands (Mottershead et al., 2015).

While waves are the dominant erosive agent, the resistance of most rock surfaces is weakened by subaerial weathering and erosion to become more sensitive to wave breaking and water movement. While rock plucking and the resulting movement of the erosion products can be observed in situ on platforms by direct surveying with, for example, unmanned aerial vehicles (Pérez-Alberti and Trenhaile, 2015), granular-scale changes are more difficult to visualise. The very small-scale wearing of rock surfaces can be accurately quantified with micrometers and microerosion meters. Such methodologies have become more common in recent decades, yet upscaling annual measurements to timeframes of significance for landform shape is difficult. Only a few studies have attempted to monitor microerosion for longer than a few years, and in this special issue Moses et al. (2015) present one of the first decade-length records of downwearing from a tropical carbonate shore. At the small granular level scale, weakening of the rock surface can be influenced by many factors, particularly the amount of wetting and drying. Wetting and drying cycles in turn can be affected by a wide range of factors, ranging from waves to cover by macroalgae. For example, laboratory experiments by Gowell et al. (2015) simulating the influence macroalgae on mudstone platforms found a reduction in the rate of mineral breakdown by as much as $79 \%$, attributed to thermal insulation and moisture retention at the rock surface. It is due to many local environmental factors and feedback loops that microerosion metre-derived downwearing cannot be simply extrapolated indefinitely into the future. This is because as a rock surface lowers it will support different biotic communities and experience greater tidal inundation which will all affect wetting and drying cycles and other subaerial processes. It therefore remains a challenge for the discipline to extrapolate short-term field observations and laboratory experiments to the millennial scale over which many rock landforms are created.

\section{Event Scale}

Infrequent weather events can also cause major landform change at the sub-metre scale. This was observed on the coast of Mesnil-Val, in NW France, where a sudden frost event in 2009 caused temperatures to drop to $-9.5^{\circ}$, causing widespread frost shattering of the shore platform (Dewez et al., 2015). In this study the authors found that six episodes of frost led to platform lowering of $0.8+/-$ $0.5 \mathrm{~mm}$ in a single winter. Such extreme events highlight how low frequency events can lead to high magnitude of change in the system at some locations.

Cliff failure is another example of the complexities of the mismatch between observational timescales and those of landform evolution. Cliff collapse leads to a sudden landward shift in the cliff top of many metres. The frequency of such events is not necessarily high, which means a single 
event cannot be used to characterise the evolutionary trajectory of a cliffed shore. New statistical techniques and utilisation of catalogues of observed cliff failure now provide great promise in reconciling these different timescales. In this Special Issue Letortu et al. (2015) developed an inventory of 331 individual landslides between 2002 and 2009 on the Upper Normandy coast of France. A thorough statistical analysis of the boundary conditions for each of these events allowed "a starting point for the prediction and prevention of the hazard of coastal chalk cliff rock falls" ( $p$ 1371). Baldassarri and Sapoval (2015) take the analysis further using Power Law statistics. Their theoretical approach yields important results as it highlights that many different physical phenomena can lead to the same type of statistical results - an important consideration for predicting rocky coast hazards where a range of boundary conditions can determine final landscape form.

\section{Geomorphic/Geological Scale}

The classic approach to understanding long term rocky coast evolution has been to use space-fortime substitution. Long sections ( $>$ kilometre-scale) are studied to quantify the variation in geomorphology to provide inferences on what drives land formation. Such large-scale studies can vary boundary conditions through investigations of sites of different geology, tide or wave climate. By confining a study to a specific boundary condition, while varying others, it is possible to both define the natural variation within a system as well as how changes in boundary conditions can determine the evolutionary pathway of a system. The spatial scale of these studies tends to be determined by the specific research question. For example Bini et al. (2014) investigated a hundredmetre stretch of the Argentinian coast to specifically quantify the relationship of erosive notches to sea level. Kennedy et al. (2014) on the other hand focussed on long term landform evolution of granitic rocky coasts, with a field site almost $100 \mathrm{~km}$ long in order to vary wave exposure while keeping the boundary conditions of rock type and tidal range constant. These two papers also highlight the methodological advances within the discipline. Bini et al. (2014) used 3D point clouds derived from field photographs. Kennedy et al. (2014) on the other hand utilised terrestrial and bathymetric aerial LiDAR combined with high resolution multibeam sounding. Such technological advances are providing a revolution in the study of rocky coasts.

Numerical modelling is a key technique for reconciling the different spatial and temporal scales of rock coast evolution. In this Special Issue there is a focus on sea stack evolution (Limber and Murray, 2015) and cliff retreat (Carpenter et al., 2015) over centuries to millennial timeframes. Trenhaile (2014) further extends the timeframe of investigation by modelling rocky coasts over millions of years, back to the Pliocene. Modelling techniques have the advantage of being able to test landscape response through experimentally modelling each boundary condition systematically. They do however require to be grounded in field data, which is often difficult as there are still large swathes of the Earth's coastline that have yet to be systematically described. 


\section{Future Directions}

A key temporal and spatial gap in research is evident in the literature and also appears in this special issue; studies over seasonal - annual timeframes for hundreds of metres to kilometre scale appear to be lacking. Some studies do include these spatial and temporal scales within their wider frameworks, yet research specifically focussed on how rocky coast systems behave at this scale appears to be lacking. A reason for this is likely that current methodological approaches are not suited for measuring change at this scale and that landform response is difficult to quantify (Figure 2). However, for models to be applicable, and for weathering and wave impacts to be upscaled in order to link the instantaneous and the long-term, a continuum of research over the entire spatial and temporal scale of land formation is required.

\section{References}

Baldassarri, A., Sapoval, B., 2015. Power law statistics of cliff failures, scaling and percolation. Earth Surface Processes and Landforms 40, 1116-1128.

Bini, M., Isola, I., Pappalardo, M., Ribolini, A., Favalli, M., Ragaini, L., Zanchetta, G., 2014. Abrasive notches along the Atlantic Patagonian coast and their potential use as sea level markers: the case of Puerto Deseado (Santa Cruz, Argentina). Earth Surface Processes and Landforms 39, 1550-1558.

Carpenter, N.E., Dickson, M.E., Walkden, M., Nicholls, R.J., Powrie, W., 2015. Lithological controls on soft cliff planshape evolution under high and low sediment availability. Earth Surface Processes and Landforms 40, 840-852.

Dewez, T.J.B., Regard, V., Duperret, A., Lasseur, E., 2015. Shore platform lowering due to frost shattering during the 2009 winter at mesnil Val, English channel coast, NW France. Earth Surface Processes and Landforms 40, 1688-1700.

Gowell, M.R., Coombes, M.A., Viles, H.A., 2015. Rock-protecting seaweed? Experimental evidence of bioprotection in the intertidal zone. Earth Surface Processes and Landforms 40, 1364-1370.

Kennedy, D.M., lerodiaconou, D., Schimel, A., 2014. Granitic coastal geomorphology: applying integrated terrestrial and bathymetric LiDAR with multibeam sonar to examine coastal landscape evolution. Earth Surface Processes and Landforms 39, 1663-1674.

Letortu, P., Costa, S., Cador, J.-M., Coinaud, C., Cantat, O., 2015. Statistical and empirical analyses of the triggers of coastal chalk cliff failure. Earth Surface Processes and Landforms 40, 1371-1386.

Limber, P.W., Murray, A.B., 2015. Sea stack formation and the role of abrasion on beach-mantled headlands. Earth Surface Processes and Landforms 40, 559-568.

Moses, C., Robinson, D., Kazmer, M., Williams, R., 2015. Towards an improved understanding of erosion rates and tidal notch development on limestone coasts in the Tropics: 10

years of micro 
erosion meter measurements, Phang Nga Bay, Thailand. Earth Surface Processes and Landforms 40, 771-782.

Mottershead, D.N., Bray, M.J., Soar, P.J., Farres, P.J., 2015. Characterisation of erosional features associated with tsunami terrains on rocky coasts of the Maltese islands. Earth Surface Processes and Landforms 40, 2093-2111.

Ogawa, H., Dickson, M.E., Kench, P.S., 2014. Hydrodynamic constraints and storm wave characteristics on a sub-horizontal shore platform. Earth Surface Processes and Landforms, n/a-n/a.

Ogawa, H., Dickson, M.E., Kench, P.S., 2015. Hydrodynamic constraints and storm wave characteristics on a sub-horizontal shore platform. Earth Surface Processes and Landforms 40, 65-77.

Pérez-Alberti, A., Trenhaile, A.S., 2015. An initial evaluation of drone-based monitoring of boulder beaches in Galicia, north-western Spain. Earth Surface Processes and Landforms 40, 105-111.

Trenhaile, A., 2014. Modelling the effect of Pliocene-Quaternary changes in sea level on stable and tectonically active land masses. Earth Surface Processes and Landforms 39, 1221-1235.

Young, A.P., Guza, R.T., O'Reilly, W.C., Burvingt, O., Flick, R.E., 2016. Observations of coastal cliff base waves, sand levels, and cliff top shaking. Earth Surface Processes and Landforms 41, 1564-1573.

\section{Figure Captions}

Figure 1: The spatial and temporal scale of articles published on rocky coasts in Earth Surface Processes and Landforms from $2014-2017$.

Figure 2: The temporal and spatial scale of the primary methodological approaches used to research cliffs and shore platforms. A gap in knowledge appears at approximately the kilometre scale over annual timescales. 


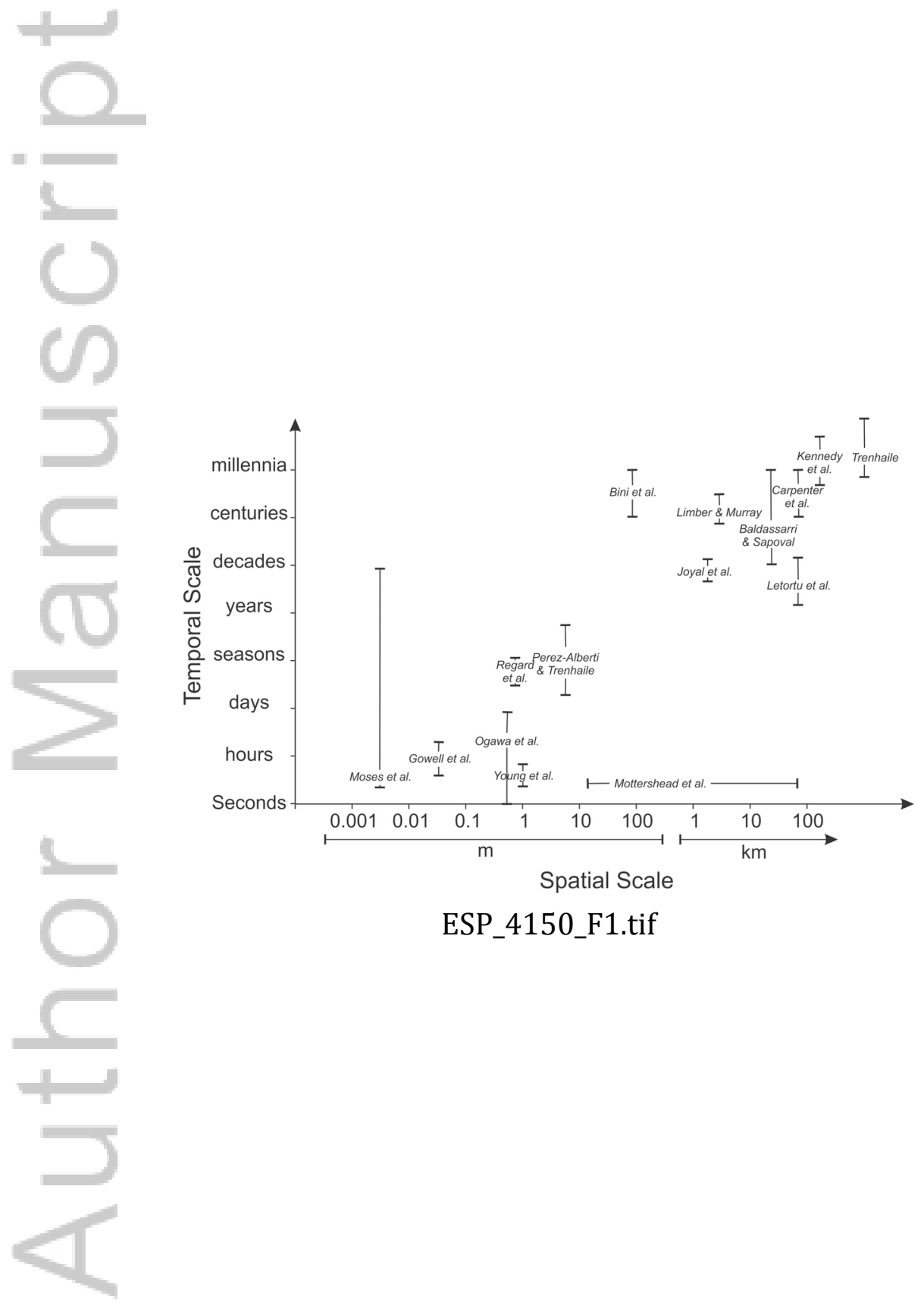

This article is protected by copyright. All rights reserved. 


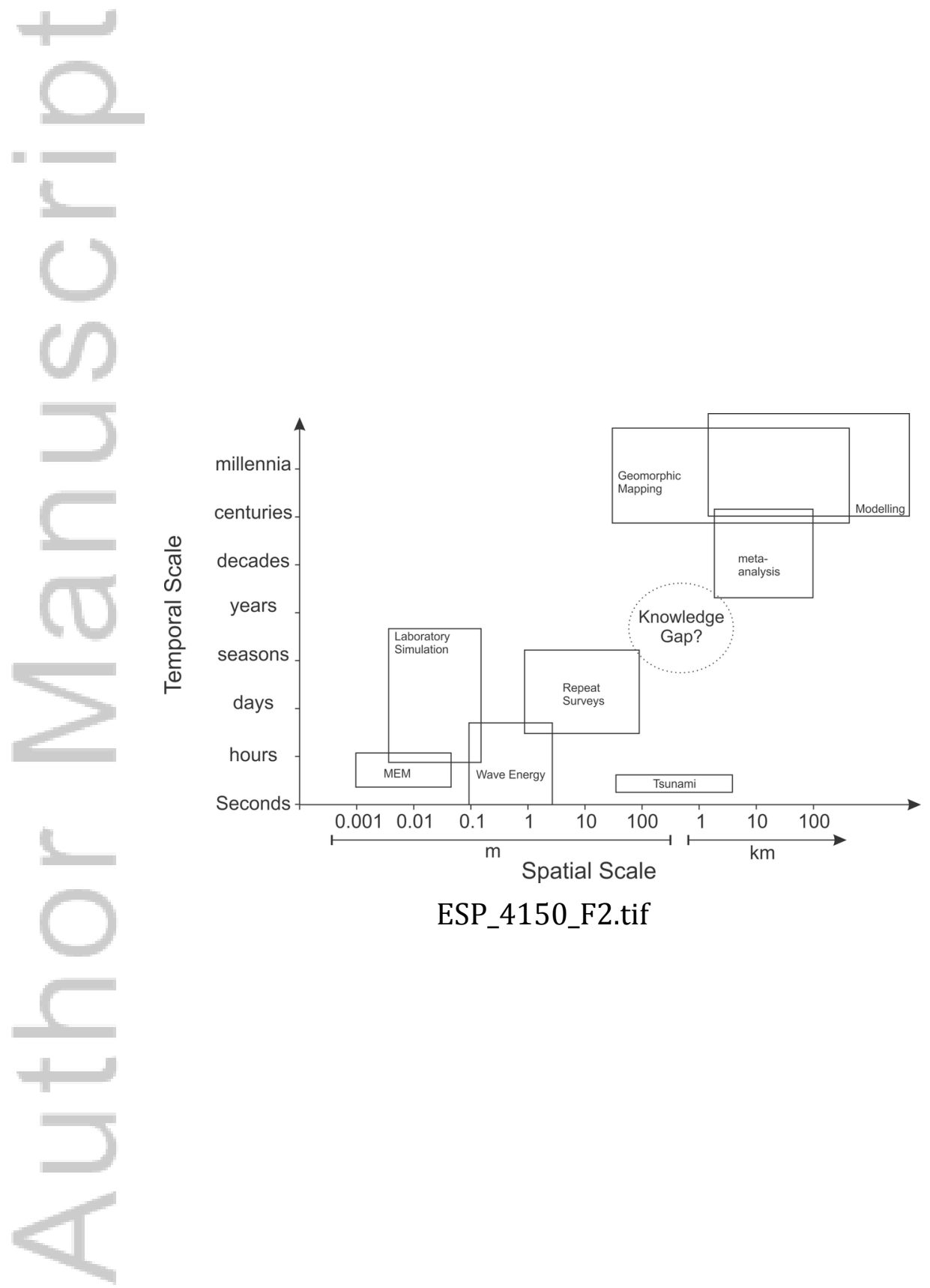

This article is protected by copyright. All rights reserved. 


\section{University Library}

\section{- M M N E R VA A gateway to Melbourne's research publications}

Minerva Access is the Institutional Repository of The University of Melbourne

Author/s:

Kennedy, DM;Coombes, MA;Mottershead, DN

Title:

The temporal and spatial scales of rocky coast geomorphology: a commentary

Date:

2017-08-01

Citation:

Kennedy, D. M., Coombes, M. A. \& Mottershead, D. N. (2017). The temporal and spatial scales of rocky coast geomorphology: a commentary. EARTH SURFACE PROCESSES AND LANDFORMS, 42 (10), pp.1597-1600. https://doi.org/10.1002/esp.4150.

Persistent Link:

http://hdl.handle.net/11343/292808 